\title{
Monitoring dan Kontrol Sistem Penyemprotan Air untuk Budidaya Aeroponik Menggunakan NodeMCU ESP8266
}

\author{
Samuel Siregar dan Muhammad Rivai \\ Departemen Teknik Elektro, Fakultas Teknologi Elektro, Institut Teknologi Sepuluh Nopember (ITS) \\ e-mail:muhammad_rivai@ee.its.ac.id
}

\begin{abstract}
Abstrak - Salah satu masalah utama yang dihadapi Indonesia di bidang pertanian adalah berkurangnya lahan pertanian akibat beralih fungsi menjadi pemukiman. Dibutuhkan sebuah metode tanam di lahan sempit, salah satunya adalah hidroponik yang menggunakan media air untuk mengalirkan nutrisi yang dibutuhkan ke akar tanaman. Namun, metode ini masih memiliki beberapa kekurangan khususnya pada penggunaan air yang kurang efisien dan tingkat aerasi pada akar yang kurang maksimal. Aeroponik sebagai modifikasi dari hidroponik mulai banyak digunakan, yaitu bertanam dengan cara membiarkan akar tanaman tergantung bebas di udara. Pemberian nutrisi dilakukan dengan cara mengubah larutan nutrisi dari wujud cair menjadi kabut yang kemudian disemprotkan ke akar tanaman. Pada penelitian telah dirancang sebuah ruang tumbuh GrowBox yang dilengkapi dengan sebuah sistem kontrol yang mengatur penyemprotan larutan nutrisi ke akar tanaman, dan dilengkapi juga dengan pemantau temperatur dan kelembapan relatif dari ruang tumbuh melalui internet. Mikrokontroler yang digunakan adalah NodeMCU ESP8266 dengan modul sensor DHT22 sebagai sensor temperatur dan kelembapan relatif, sensor HC-SR04 untuk mendeteksi ketinggian air, ultrasonic atomizer sebagai pengubah wujud larutan nutrisi menjadi kabut, kipas DC sebagai pendistribusi kabut dan pompa DC untuk memompa larutan nutrisi. Hasil percobaan menunjukkan bahwa sensor DHT22 dapat mengukur kelembaban relatif dan temperatur GrowBox dengan error $1,54 \%$ dan menjadi sinyal perintah bagi aktuator untuk bekerja. Sensor HC-SR04 dapat mendeteksi level nutrisi dengan error $0,09 \mathrm{~cm}$, dan ultrasonic atomizer dapat mengubah larutan nutrisi menjadi kabut yang dapat meningkatkan nilai kelembaban GrowBox yang dirancang sesuai nilai yang ditentukan yaitu $85 \%$.
\end{abstract}

Kata Kunci-Aeroponik, DHT22, NodeMCU ESP8266, Ultrasonic Atomizer.

\section{PENDAHULUAN}

$\mathrm{B}$ ERADA pada kawasan yang strategis dan beriklim tropis seharusnya menjadi keunggulan tersendiri bagi Indonesia khususnya dalam bidang pertanian. Namun ternyata hasil pertanian Indonesia sendiri belum maksimal. Bahkan untuk beberapa komoditas Indonesia masih melakukan impor dari negara lain. Salah satu penyebab rendahnya hasil pertanian Indonesia yang paling terlihat adalah semakin berkurangnya lahan pertanian akibat peralihan fungsi lahan menjadi pemukiman. Data Luas Lahan Sawah Menurut Provinsi pada kurun waktu 2003-2014 ditunjukkan pada Gambar 1 [1].

Gambar 2 mengilustrasikan konsep urban farming untuk menjadi salah satu solusi masalah keterbatasan lahan ini. Urban farming adalah usaha bercocok tanam di lahan-lahan sempit kosong yang biasanya ada di perkotaan, seperti pada atap, teras, balkon, bahkan dinding [2]. Salah satu metode tanam yang sudah popular dan banyak digunakan untuk melakukan urban farming adalah hidroponik. Hidroponik adalah metode untuk menumbuhkan tanaman dengan cara memberikan larutan nutrisi yang diatur agar sesuai dengan tanaman tanpa media tanam tanah [2][3].

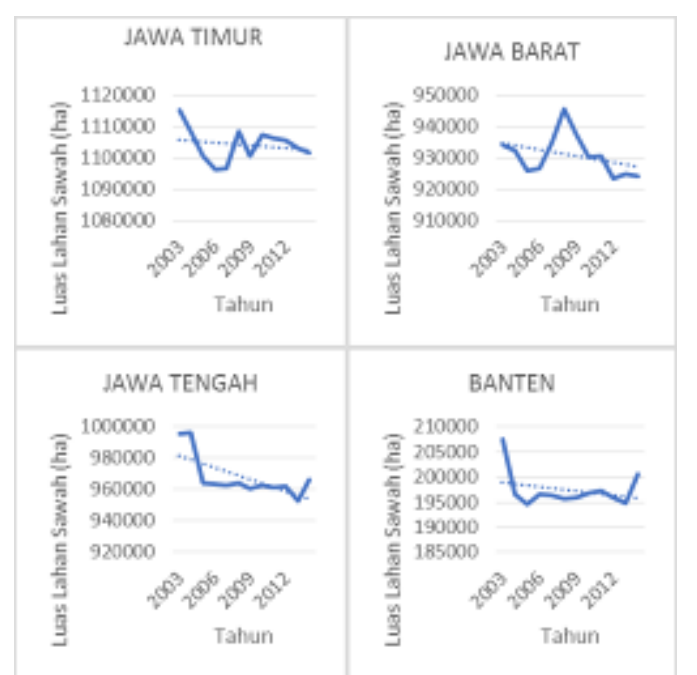

Gambar 1. Grafik laju perubahan luas lahan sawah (ha) di beberapa provinsi di Pulau Jawa.

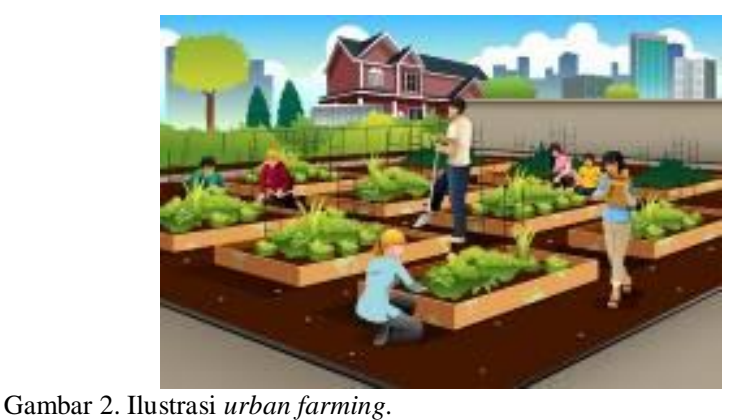

Dengan metode ini, tanaman mendapat asupan nutrisi dari larutan nutrisi yang dialirkan secara kontinyu melewati akar tanaman. Teknik hidroponik memiliki kelebihan dalam hal efisiensi penggunaan lahan karena semua kebutuhan nutrisi tanaman sudah tersedia pada larutan nutrisi yang dialirkan. Namun, teknik ini masih memiliki kekurangan, khususnya pada tingkat oksigenisasi akar tanaman yang rendah akibat akar tanaman yang selalu terendam larutan nutrisi. Selain itu, kadar nutrisi dalam larutan juga butuh perhatian khusus agar tidak terlalu sedikit karena akan menyebabkan pertumbuhan 
yang maksimal, juga tidak dapat terlalu pekat karena akan menyebabkan sulit untuk diserap akar tanaman, dan akan memiliki efek beracun pada tanaman [3].

Teknik bertanam lain yang mulai banyak digunakan adalah aeroponik, yaitu memanfaatkan semprotan larutan nutrisi berwujud kabut ke akar tanaman yang menggantung di udara. Dengan teknik cocok tanam ini, kekurangan hidroponik sebelumnya dapat diatasi. Namun, teknik ini memiliki kerumitan yang lebih tinggi. Akar tanaman aeroponik harus selalu mendapat semprotan larutan nutrisi agar tidak kering dan menjadi layu. Selain itu, intensitas semprotan juga harus diatur agar tidak terlalu sedikit maupun terlalu banyak sehingga akar tanaman dapat menyerap nutrisi yang diberikan dengan maksimal.

\section{DASAR TEORI}

\section{A. Aeroponik}

Aeroponik adalah sebuah teknik bertanam dengan cara menggantung akar tanaman tersebut di udara dan tumbuh di lingkungan lembab tanpa tanah, seperti ditunjukkan pada Gambar 3. Karena akarnya digantungkan di udara, dan tidak memerlukan tanah, maka memungkinkan teknik ini untuk dilakukan hampir di mana saja [4]. Aeroponik berasal dari kata aero yang berarti udara dan ponus yang berarti daya, sehingga aeroponik sendiri bermakna memberdayakan udara. Aeroponik pada dasarnya merupakan modifikasi dari teknik bertanam hidroponik. Jika pada teknik bertanam hidroponik larutan nutrisi untuk tanaman disirkulasikan dengan cara mengalirkannya, pada teknik aeroponik larutan nutrisi disemprotkan dalam bentuk kabut hingga mengenai akar tanaman. Performa sistem bercocok tanam aeroponik berpotensi untuk melebihi metode konvensional [5]. Secara umum keuntungan sistem aeroponik dibandingkan dengan sistem budidaya lain, diantaranya: 1) menggunakan jauh lebih sedikit air; 2) memberikan ketersediaan air yang seragam bagi tanaman sepanjang tahun; 3) memudahkan pengamatan umbi dan pemanenan umbi lebih nyaman dan bersih; 4) mengoptimalkan aerasi pada akar; 5) memungkinkan produksi intensif dalam area yang terbatas.

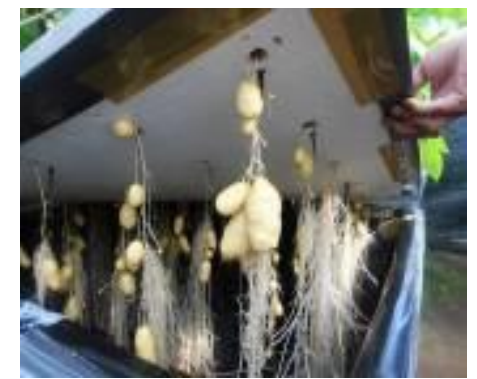

Gambar 3. Akar Tanaman Aeroponik.

Sistem Aeroponik mengoptimalkan aerasi akar yang dapat meningkatkan hasil dibandingkan dengan hidroponik [6].

Namun di balik keunggulannya, terdapat juga beberapa kekurangan dari aeroponik. Salah satu penyebab teknik bertanam aeroponik kurang populer adalah karena tingkat kerumitan yang cukup tinggi dalam penerapannya. Salah satu solusi yang dapat mengatasi masalah kerumitan perawatan tanaman dengan teknik aeroponik ini adalah dengan mengaplikasikan beberapa sensor untuk memantau faktor faktor lingkungan yang mempengaruhi perkembangan dari tanaman. Beberapa faktor lingkungan yang mempengaruhi pertumbuhan dan perkembangan tanaman diantaranya adalah: 1) temperatur; 2) kelembapan; 3) intensitas cahaya; 4) kadar $\mathrm{O}_{2}$ dan $\mathrm{CO}_{2}$; dan 5) kecepatan dan arah angin [6]. Kondisi kelembaban yang biasanya digunakan untuk teknik bertanam aeroponik adalah sekitar 70\% - 80\% [5][7], sedang temperatur yang biasa digunakan pada teknik bertanam aeroponik berkisar antara $26^{\circ} \mathrm{C}$ sampai $30^{\circ} \mathrm{C}$.

\section{B. Nutrisi}

Nutrisi tanaman terlarut dalam air yang digunakan dalam hidroponik, yang juga digunakan dalam aeroponik, sebagian besar anorganik dan dalam bentuk ion. Nutrisi utama tersebut diantaranya dalam bentuk kation terlarut (ion bermuatan positif), yakni $\mathrm{Ca}^{2+}$ (kalsium), $\mathrm{Mg}^{2+}$ (magnesium), dan $\mathrm{K}^{+}$ (kalium); larutan nutrisi utama dalam bentuk anion adalah $\mathrm{NO}^{3-}$ (nitrat), $\mathrm{SO}_{4}{ }^{2-}$ (sulfat), dan $\mathrm{H}_{2} \mathrm{PO}_{4}^{-}$(dihidrogen fosfat). Unsur hara makro meliputi kalium nitrat, kalsium nitrat, kalium fosfat, dan magnesium sulfat. Unsur hara mikro diantaranya $\mathrm{Fe}$ (besi), Mn (mangan), $\mathrm{Cu}$ (tembaga), $\mathrm{Zn}$ (seng), $\mathrm{B}$ (boron), $\mathrm{Cl}$ (klorin), dan $\mathrm{Ni}$ (nikel). Unsur hara makro dibutuhkan dalam jumlah besar dan konsentrasinya dalam larutan relatif tinggi, sementara unsur hara mikro hanya diperlukan dalam konsentrasi yang rendah. Dalam prakteknya, untuk kemudahan dalam memenuhi kebutuhan akan unsurunsur di atas, digunakan Nutrisi $A B$ mix seperti yang ditunjukkan pada Gambar 4, yaitu formulasi yang mengandung unsur hara esensial yang dibutuhkan tanaman.

\section{Ultrasonic Atomizer}

Atomizer atau mist maker adalah alat yang digunakan untuk menghasilkan kabut atau butiran air berukuran sangat kecil (dalam orde mikro) dari sejumlah cairan. Pada penelitian ini digunakan transduser ultrasonik sebagai penghasil kabut. Transduser ultrasonik sendiri adalah komponen elektronik yang bisa mengubah energi listrik menjadi energi mekanik berupa gelombang ultrasonik (frekuensi di atas $20 \mathrm{KHz}$ ) dengan cara menggetarkan sebuah membran atau lapisan tipis.

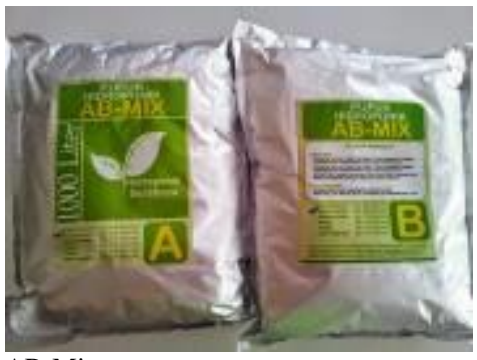

Gambar 4. Nutrisi AB-Mix.

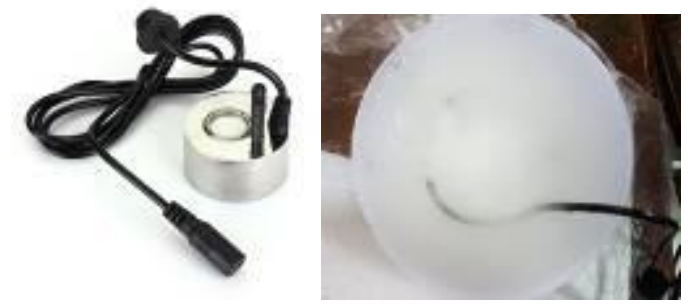

Gambar 5. Ultrasonic atomizer dan kabut yang dihasilkan. 
Ketika mengsonikasi cairan pada intensitas tinggi, gelombang suara yang merambat ke dalam cairan mengakibatkan tekanan balik yang tinggi (kompresi) dan siklus bertekanan rendah (penjernihan), dengan tingkat yang tergantung pada frekuensi. Selama siklus bertekanan rendah, intensitas gelombang ultrasonik yang tinggi membuat gelembung-gelembung vakum kecil atau void dalam cairan. Ketika gelembung mencapai volume di mana tak dapat lagi menyerap energi, gelembung runtuh dengan keras selama dalam siklus bertekanan tinggi. Efek ini disebut kavitasi [8] [9]. Ultrasonic atomizer memanfaatkan efek ini untuk menghasilkan kabut seperti yang ditunjukkan pada Gambar 5.

\section{Sensor Temperatur dan Kelembaban DHT22}

Sensor DHT-22 adalah sensor yang dapat mendeteksi kelembaban dan temperatur relative, ditunjukkan pada Gambar 6. Sensor ini menggunakan sensor kelembaban kapasitif yang bekerja menggunakan konsep kapasitor [10], dan thermistor untuk mengukur udara di sekitarnya. Sensor ini memiliki tingkat stabilitas yang baik serta keakuratan yang lebih tinggi [11].

\section{E. Sensor Jarak HC-SR04}

HC-SR04 adalah modul sensor pengukur jarak dengan gelombang ultrasonic, ditunjukkan pada Gambar 7. Modul ini memancarkan seberkas sinyal ultrasonik berbentuk pulsa, kemudian jika ada objek di depan sensor maka penerima akan menerima pantulan sinyal ultrasonik yang terhalang objek tersebut. Penerima akan membaca lebar pulsa (dalam bentuk PWM) yang dipantulkan objek dan selisih waktu pemancaran.

\section{F. NodeMCU ESP8266}

NodeMCU ESP8266 dev. board yang ditunjukkan pada Gambar 8 pada dasarnya adalah pengembangan dari System on Chip ESP8266-12E, dengan firmware berbasis e-Lua, dilengkapi dengan micro USB port untuk pemrograman dan suplai daya, juga dilengkapi dengan tombol push button reset dan flash [12][13].

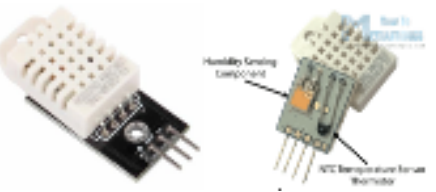

Gambar 6. Sensor DHT22 dan penyusunnya.
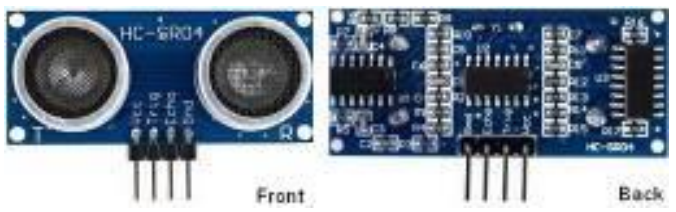

Gambar 7. Modul sensor HC-SR04.

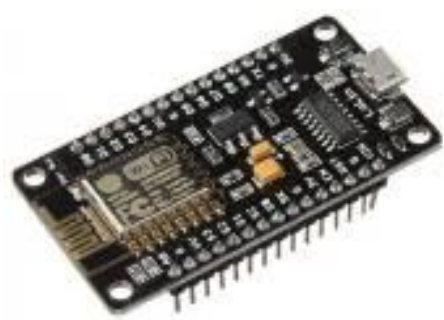

Gambar 8. NodeMCU ESP8266 dev. Board.
NodeMCU ESP8266 menawarkan kemudahan untuk melakukan pengembangan perangkat berbasis internet karena sudah dilengkapi modul komunikasi wireless (WiFi). Ketika lebih dari satu perangkat NodeMCU ESP8266 dengan sensor bekerja bersama, dapat dikategorikan sebagai Wireless Sensor Network [14][15].

\section{G. Internet of Things (IoT)}

Internet of Things (IoT) adalah sebuah sistem dimana benda-benda di dunia fisik dapat dihubungkan ke internet oleh sensor. IoT mengacu pada penggunaan perangkat dan sistem cerdas yang terhubung untuk memanfaatkan data yang dikumpulkan oleh sensor dan aktuator yang tertanam di mesin dan benda fisik lainnya [16][17]. Untuk memaksimalkan produktivitas tanaman aeroponik dibutuhkan informasi tentang kondisi lingkungan di sekitar lahan tanam seperti tingkat kelembaban dan temperatur untuk membuat keputusan tentang kontrol yang harus dilakukan pada tanaman.

\section{H. Blynk}

Blynk adalah sebuah layanan server yang digunakan untuk mendukung Internet of Things. Layanan server ini dapat digunakan oleh pengguna smartphone berbasis Android maupun iOS. Terdapat 3 komponen utama Blynk, yaitu: 1) Blynk Apps, memungkinkan perancangan antarmuka dengan berbagai komponen input output yang mendukung pengiriman maupun penerimaan data serta merepresentasikannya. Representasi data dapat berbentuk visual angka maupun grafik; 2) Blynk Server, yaitu fasilitas backend service berbasis cloud yang bertanggung jawab mengatur komunikasi antara aplikasi dengan hardware; dan 3) Blynk Library, yang digunakan untuk pengembangan kode. Blynk library tersedia untuk banyak platform perangkat keras (termasuk NodeMCU ESP8266) sehingga semakin memudahkan para pengembang IoT dengan fleksibilitas hardware yang didukung oleh lingkungan Blynk. Hubungan antar komponen ini dengan hardware ditunjukkan pada Gambar 9.

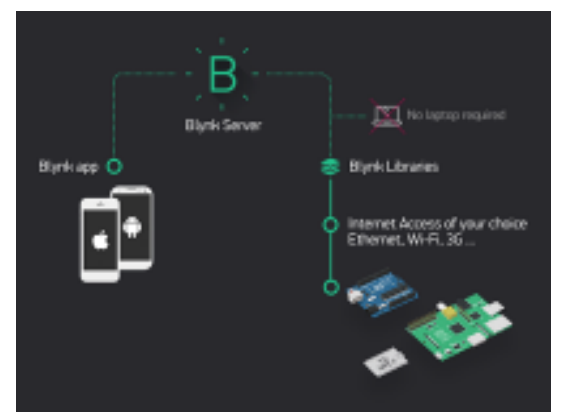

Gambar 9. Hubungan antar komponen menggunakan Blynk.

\section{PERANCANGAN SISTEM}

Rancangan terbagi menjadi dua bagian utama, yaitu rancangan perangkat keras (hardware) dan perangkat lunak (software).

\section{A. Rancangan Perangkat Keras}

Rancangan meliputi perancangan ruang tumbuh GrowBox yang akan menjadi tempat tanaman bertumbuh (Gambar 10), perancangan rangkaian elektronik berupa breakout board dari development board NodeMCU ESP8266 agar pemasangan 
sensor DHT22 dan sensor HC-SR04 beserta aktuator (ultrasonic atomizer, kipas DC, dan pompa DC) dapat dilakukan dengan mudah.

Kriteria ruang yang dapat digunakan oleh tanaman untuk dapat tumbuh dengan baik diantaranya: 1) jarak penutup dan dasar kotak minimal $20 \mathrm{~cm}$ agar akar dapat tumbuh dengan baik; 2) tidak terhalangi agar kabut larutan nutrisi tersebar dengan baik; 3) dapat menjaga kestabilan temperatur; 4) tertutup (cahaya dari luar tidak tembus ke dalam kotak). Gambar 11 menunjukkan hubungan antar perangkat keras dalam sistem kontrol ini. Otak dari sistem pengontrolan penyemprotan larutan nutrisi ini adalah NodeMCU ESP8266 yang akan membaca masukan data dari sensor DHT22 berupa nilai temperatur dan kelembapan relatif lingkungan sekitar. Kipas DC dan ultrasonic atomizer digunakan untuk meningkatkan kelembaban relatif ruang tumbuh agar berada di atas nilai minimal yang kontrolnya diatur dengan kontrol waktu proporsional [18]. Sensor ultrasonik HC-SR04 digunakan untuk mendeteksi ketinggian larutan nutrisi dari permukaan ultrasonic atomizer dan pompa DC akan memompa larutan nutrisi dari tangki cadangan. NodeMCU ESP8266 juga akan melakukan koneksi dengan layanan Blynk sehingga pengguna dapat memantau dan mengatur sistem melalui internet.

\section{B. Rancangan Perangkat Lunak}

Rancangan meliputi desain antarmuka dengan Blynk Apps pada smartphone (berbasis iOS maupun Android) sebagai bagian dari monitoring system serta perancangan algoritma program kontrol penyemprotan berdasarkan nilai kelembaban.

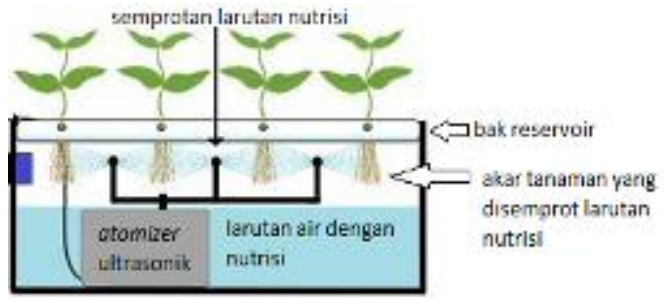

Gambar 10. Rancangan ruang tumbuh GrowBox.

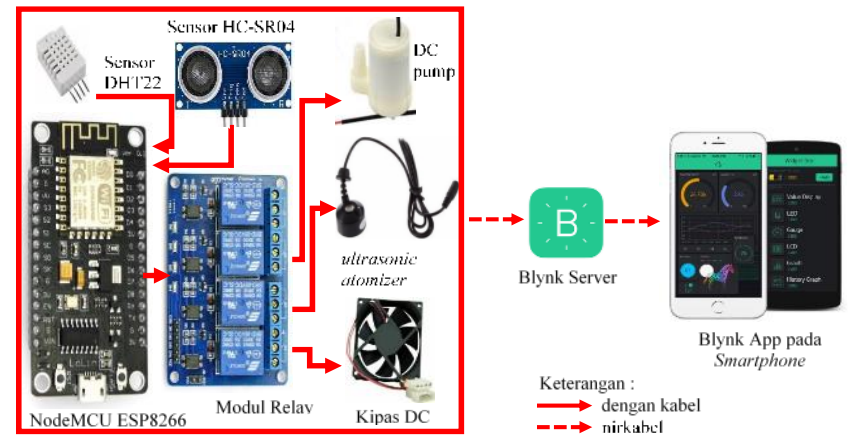

Gambar 11. Hubungan antar komponen.

Sistem kontrol penyemprotan larutan nutrisi ini diprogram menggunakan Arduino IDE serta beberapa library yaitu: 1) Blynk library sebagai penghubung perangkat dengan layanan Blynk; 2) library DHT22 untuk mengeksekusi pembacaan data sensor DHT22; 3) library ArduinoOTA yang menjembatani Arduino IDE dengan NodeMCU ESP8266 sehingga dapat diprogram melalui jaringan WiFi yang sama; dan 4) library PID_v1 sebagai kontrol waktu proporsional.
Flowchart pada Gambar 12 menunjukkan algoritma kontrol penyemprotan. Proses pertama adalah inisialisasi program dan koneksi perangkat ke jaringan WiFi. Kemudian dilakukan pembacaan data sensor DHT22. Penyemprotan dilakukan jika nilai kelembapan kurang dari $85 \%$. Kemudian ketinggian bak nutrisi dideteksi. Jika kurang dari $5 \mathrm{~cm}$ maka pompa DC akan aktif. Rutin terakhir adalah menampilkan data sensor dan status tiap aktuator pada antarmuka di aplikasi Blynk.

Antarmuka dirancang dengan menggunakan Blynk Apss yang terpasang pada smartphone. Hasil akhir perancangan ditunjukkan Gambar 13.

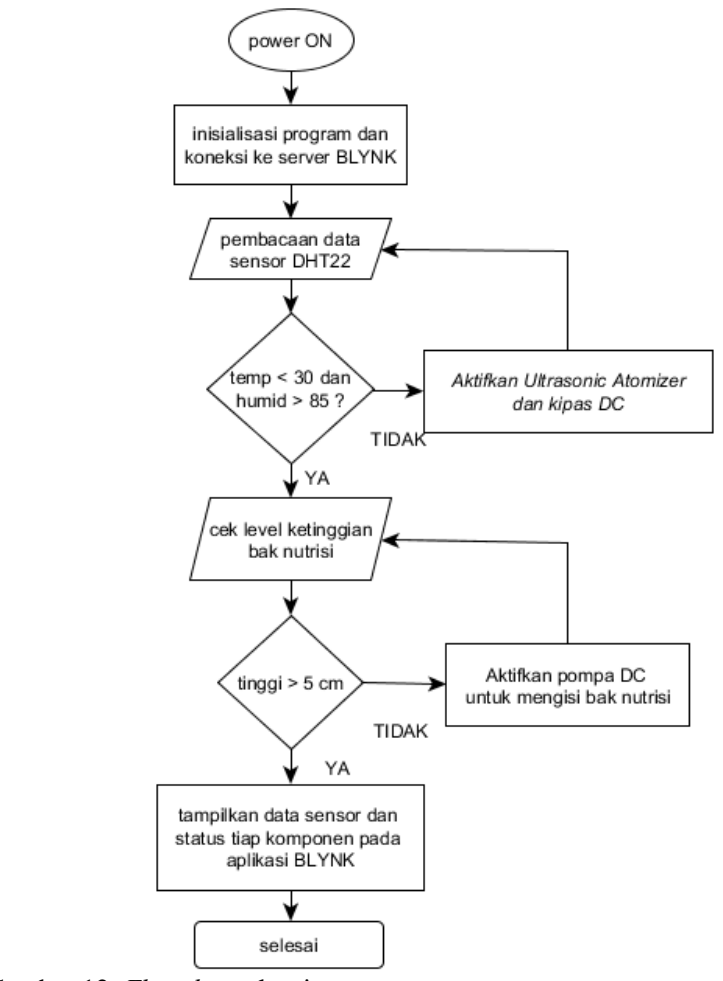

Gambar 12. Flowchart algoritma program.

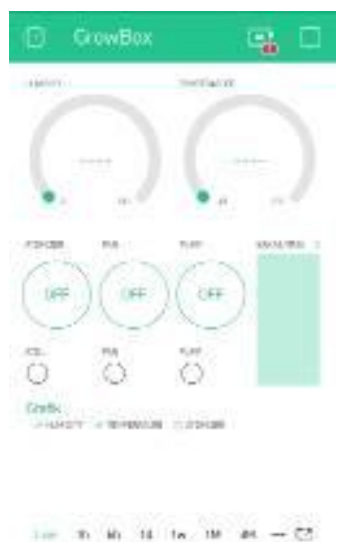

Gambar 13. Desain akhir antarmuka sistem monitoring.

\section{PENGUJIAN DAN PEMBAHASAN}

\section{A. Realisasi Rancangan Ruang Tumbuh}

Kotak styrofoam dipilih karena memenuhi kriteria ruang tumbuh yang diperlukan. Kotak yang digunakan berukuran 35L dengan dimensi 51 x 37,5 x $35 \mathrm{~cm}$ dan dilubangi menjadi 
9 - 12 lubang pot, pada bagian dalam diberi sekat untuk peletakan kipas DC agar kabut dapat tersirkulasi. Gambar 14 menunjukkan hasil akhir rancangan ruang tumbuh.

\section{B. Pengujian Ultrasonic Atomizer}

Ultrasonic atomizer yang digunakan adalah model generik dengan spesifikasi tertera dapat mengubah cairan menjadi kabut sebanyak $400 \mathrm{ml} / \mathrm{jam}$. Namun dari pengujian yang dilakukan menggunakan tabung berdiameter $10 \mathrm{~cm}$ dan tinggi $15 \mathrm{~cm}$, didapat hasil ultrasonic atomizer yang digunakan hanya dapat mengubah larutan nutrisi menjadi kabut sebanyak $\pm 120 \mathrm{ml} / \mathrm{jam}$. Dari hasil pengujian juga didapat ketinggian cairan dari atas permukaan ultrasonic atomizer agar bekerja optimal adalah sekitar 1,2 cm-7,2 cm (Gambar 15).

\section{Pengujian kipas DC}

Kipas DC yang digunakan memiliki spesifikasi ukuran $8 \mathrm{~cm} \times 8 \mathrm{~cm}$, catu daya 12VDC / 0.1A. Hasil pengujian menunjukkan kipas DC dapat bekerja dengan baik untuk mendistribusikan kabut yang dihasilkan ultrasonic atomizer.

\section{Pengujian Sensor DHT 22}

Pengujian dilakukan dengan melihat nilai yang ditampilkan oleh antarmuka pada aplikasi Blynk, apakah terdapat (yang berarti sensor bekerja) atau bernilai 0 (berarti tidak ada data sensor terbaca / diterima NodeMCU ESP8266). Gambar 16 menunjukkan grafik pembacaan sensor DHT 22 dengan temperatur rata-rata sekitar $32^{\circ} \mathrm{C}$ dan kelembapan sekitar $90 \%$.

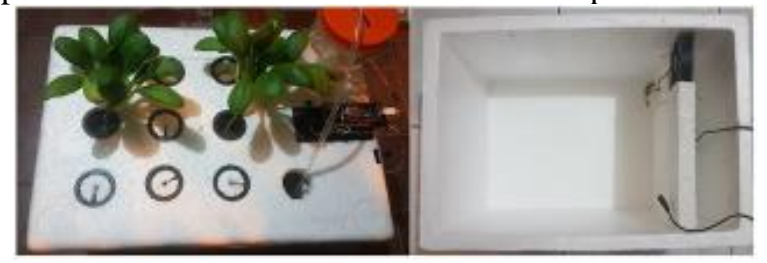

Gambar 14. Ruang tumbuh dengan 9 lubang pot.
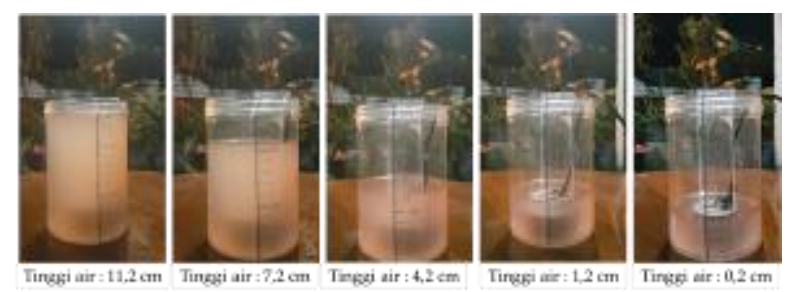

Gambar 15. Pengujian ketinggian optimal cairan.

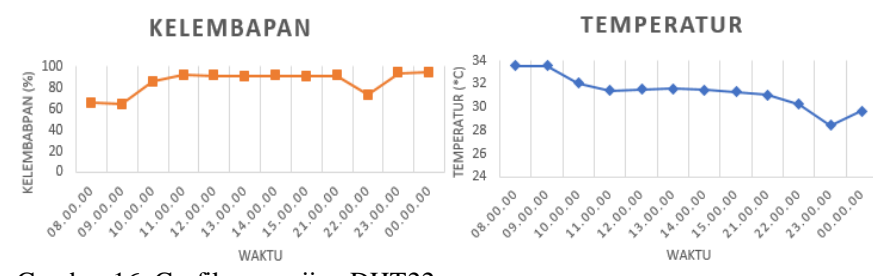

Gambar 16. Grafik pengujian DHT22.

Tabel 1.

Perbandingan sensor DHT22 dan sensor komersil

\begin{tabular}{lllllll}
\hline \hline \multirow{2}{*}{ No } & DHT22 & \multicolumn{3}{c}{ Sensor Komersil } & \multicolumn{2}{c}{ Perbedaan } \\
\cline { 2 - 7 } & Temp. & Humid. & Temp. & Humid. & Temp. & Humid. \\
\hline 1 & 31,1 & 51,4 & 31,1 & 51 & 0 & 0,4 \\
2 & 30,9 & 53,8 & 31,0 & 52 & 0,1 & 1,8 \\
3 & 30,7 & 53,2 & 30,9 & 51 & 0,2 & 2,2 \\
4 & 30,6 & 54,1 & 30,8 & 52 & 0,2 & 2,1 \\
5 & 30,7 & 53,5 & 30,9 & 52 & 0,2 & 1,5 \\
\hline \hline
\end{tabular}

Tabel 2 .

Pengujian pembacaan sensor HC-SR04

\begin{tabular}{cccc}
\hline $\begin{array}{c}\text { Percobaan } \\
\text { ke- }\end{array}$ & $\begin{array}{c}\text { Pembacaan Sensor } \\
(\mathrm{cm})\end{array}$ & $\begin{array}{c}\text { Nilai Asli } \\
(\mathrm{cm})\end{array}$ & $\begin{array}{c}\text { Selisih } \\
(\mathrm{cm})\end{array}$ \\
\hline 1 & 0,02 & 0 & 0,02 \\
2 & 0,93 & 0,9 & 0,03 \\
3 & 2,17 & 2 & 0,17 \\
4 & 3,2 & 3,2 & 0 \\
5 & 4,23 & 4,25 & 0,02 \\
6 & 5,33 & 5,1 & 0,23 \\
7 & 6,29 & 6,5 & 0,21 \\
\hline \hline
\end{tabular}

Selain itu, pengujian dilakukan juga perbandingan nilai pembacaan antara sensor DHT 22 dengan sensor kelembaban dan temperatur yang dijual di pasaran (komersil). Hasilnya dapat dilihat pada Tabel 1 . Hal ini menunjukkan bahwa nilai pembacaan sensor DHT22 tidak jauh berbeda dengan sensor komersil dengan rata-rata error pembacaan temperatur $0,14 \%$ dan rata-rata error pembacaan kelembaban $1,54 \%$.

\section{E. Pengujian Sensor HC-SRO4}

Pengujian sensor HC-SR04 dilakukan dengan menggunakan tabung berdiameter $10 \mathrm{~cm}$ dan tinggi $15 \mathrm{~cm}$ yang diberi garis pengukur. Hasil pengujian dapat dilihat pada Tabel 2. Pembacaan sensor menunjukkan hasil yang cukup akurat dengan error rata-rata $0.09 \mathrm{~cm}$.

\section{F. Pengujian Penggunaan Ultrasonic Atomizer dan DC Fan}

Pengujian dilakukan untuk mengetahui pengaruh dari penggunaan ultrasonic atomizer dan kipas DC terhadap temperatur dan kelembaban GrowBox. Dari pengujian yang dilakukan, terjadi kenaikan kelembaban relatif di dalam ruang dari $58 \%$ menjadi $86 \%$, dan penurunan temperatur dari $35,6^{\circ} \mathrm{C}$ menjadi $28,6^{\circ} \mathrm{C}$, ditunjukkan pada Gambar 17 . Ini berarti ultrasonic atomizer dan kipas DC dapat meningkatkan kelembaban di dalam ruang tumbuh GrowBox dan juga menurunkan temperatur. Tabel 3 menunjukkan keluaran dari kontrol waktu proporsional, dimana semakin kecil nilai kelembaban maka semakin lama durasi ultrasonic atomizer bekerja, dan sebaliknya.

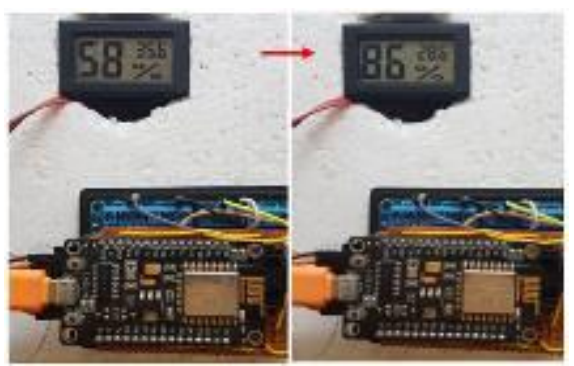

Gambar 17. Terjadi perubahan kelembaban dan temperatur setelah sistem dijalankan.

Tabel 3.

Keluaran dari kontrol waktu proporsional

\begin{tabular}{cccc}
\hline \hline No. & Temperatur & Kelembapan & Output kontrol on \\
\hline 1 & 35,8 & 47,9 & 154,20 \\
2 & 36,9 & 48,1 & 153,80 \\
3 & 32,9 & 56,5 & 137,00 \\
4 & 32,5 & 58,1 & 133,80 \\
5 & 32,5 & 60,4 & 129,20 \\
6 & 32,7 & 61,1 & 127,80 \\
7 & 32,5 & 62,4 & 125,20 \\
8 & 32,3 & 64,7 & 120,60 \\
9 & 36,8 & 67,1 & 115,80 \\
10 & 36,9 & 74,2 & 101,60 \\
\hline \hline
\end{tabular}




\section{KESIMPULAN}

Berdasarkan hasil perancangan dari monitoring dan kontrol sistem penyemprotan air untuk budidaya aeroponik menggunakan Nodemcu ESP8266, didapatkan hasil bahwa penggunaan NodeMCU ESP8266 sebagai pengontrol aktuator berupa ultrasonic atomizer, kipas DC, dan pompa DC berdasarkan nilai pembacaan sensor DHT 22 dan HC-SR04 dapat dilakukan. Durasi on dan off ultrasonic atomizer diatur oleh kontrol proporsional, semakin kecil nilai kelembaban maka semakin lama durasi ultrasonic atomizer bekerja. Nilai kelembaban ruang tumbuh yang dirancang dapat meningkat dari $61 \%$ menjadi $85 \%$ dalam waktu 47 detik. Pompa DC bekerja jika ketinggian larutan nutrisi pada bak nutrisi kurang dari $5 \mathrm{~cm}$.

\section{DAFTAR PUSTAKA}

[1] BPS Indonesia, "Data Luas Lawah Sawah per Provinsi," Badan Pusat Statistik, 2018.

[2] P. Crisnapati, I. Wardana, I. Aryanto, and A. Hermawan, "Hommons: Hydroponic management and monitoring system for an IOT based NFT farm using web technology," in 5th International Conference on Cyber and IT Service Management (CITSM), 2017.

[3] D. Eridani, O. Wardhani, and E. Widianto, "Designing and implementing the arduino-based nutrition feeding automation system of a prototype scaled nutrient film technique (NFT) hydroponics using total dissolved solids (TDS) sensor," in 4th International Conference on Information Technology, Computer, and Electrical Engineering (ICITACEE), 2017.

[4] A. Wicaksono, E. Widasari, and F. Utaminingrum, "Implementasi Sistem Kontrol dan Monitoring $\mathrm{pH}$ pada Tanaman Kentang Aeroponik secara Wireless," J. Pengemb. Teknol. Inf. Dan Ilmu Komput., vol. 1, no. 5, pp. 386-398, 2017.

[5] I. Idris and M. I. Sani, "Monitoring and control of aeroponic growing system for potato production," in IEEE Conference on Control, Systems \& Industrial Informatics, 2012.

[6] N. Rosdiana, Sugiyono, and L. Prayoga., "Studi Pengaruh Nutrisi Aeroponik Terhadap Pertumbuhan Tajuk Kentang Kultivar Granola," Univeristas Jenderal Soedirman, 2014.

[7] A. Subandi, "Rancang Bangun Sistem Aeroponik Secara Otomatis Berbasis Mikrokontroler," in SENIATI, 2016.

[8] S. Nainggolan, "Peran Kavitasi Hidrodinamik dan Kavitasi Ultrasonik pada Penyisihan Fenol dengan Proses Oksidasi Lanjut Berbasis Ozon,” 2010.

[9] T. Leong and S. Ashokkumar, Muthupandian, Kentish, "The fundamentals of power ultrasound-A review," 2011.

[10] R. Setiawan, M. Rivai, and Suwito, "Implementasi Analog Front End pada Sensor Kapasitif untuk Pengaturan Kelembaban Menggunakan Mikrokontroller STM 32," J. Tek. ITS, vol. 6, no. 1, 2017

[11] A. Saptadi, "Perbandingan Akurasi Pengukuran Suhu dan Kelembapan Antara Sensor DHT11 dan DHT22," J. INFOTEL Inform. Telekomun. Elektron., vol. 6, no. 2, p. 49, 2014.

[12] R. Vina and E.T. Aan, "Sistem Pengendali Pintu Berbasis Web Menggunakan NodeMCU 8266," STMIK AKAKOM, 2017.

[13] R. Kodali and B. Sarjerao, "A low cost smart irrigation system using MQTT protocol," in IEEE Region 10 Symposium (TENSYMP), 2017.

[14] N. Arsyistawa, M. Rivai, and S. Suwito, "Aplikasi Wireless Sensor Network Untuk Pembacaan Meteran Air," J. Tek. ITS, vol. 6, no. 2, pp. A807-812, Oct. 2017.

[15] M. Dzukifli, M. Rivai, and Suwito, "Rancang Bangun Sistem Irigasi Tanaman Otomatis menggunakan Wireless Sensor Network," $J$. Tek. ITS, vol. 5, no. 2, 2016

[16] M. Gumelar, M. Rivai, and Tasripan, "Rancang Bangun Wireless Electronic Nose Berbasis Teknologi Internet of Things," J. Tek. ITS, vol. 6, no. 2, 2017.

[17] J. Pitakphongmetha, N. Boonnam, S. Wongkoon, T. Horanont, D. Somkiadcharoen, and J. Prapakornpilai, "Internet of things for planting in smart farm hydroponics style," in International Computer Science and Engineering Conference (ICSEC), 2016.

[18] M. Lori, "Understanding Time Proportional Control," 2018. 